Chapter 4

\title{
Coping Strategies and Parents' Positive Perceptions of Raising a Child with Autism Spectrum Disorders
}

\author{
Encarnación Sarriá and Pilar Pozo \\ Additional information is available at the end of the chapter \\ http://dx.doi.org/10.5772/58966
}

\section{Introduction}

Autism spectrum disorder (ASD) is a developmental disorder of organic origin characterised by impairment and deficits in social interaction and communication as well as repetitive and restricted patterns of behaviour [1]. ASD can manifest with very different degrees of severity, but most children with autism have special needs in all aspects of their development and in all contexts. Associated problems such as intellectual deficit, sensory issues, problems with eating and sleeping and behavioural problems are also common in ASD and may cause as much impairment as the core features of the disorder [2-5].

Therefore, autism is considered one of the developmental disorders that has the greatest impact on the family. Raising and caring for a child with autism is a daunting and permanent challenge for parents and primary caregivers. Parents often need to adapt their professional lives and relationships in order to find appropriate solutions that are suited to the specific needs of their child [6]. A large number of studies have consistently found that parents of children with ASD have higher levels of stress, anxiety and depression than parents of typically developed children or children with other disorders [7-13].

However, previous research also reports large differences in the adaptation of families to ASD. Despite the difficulties of caring for a child with ASD, many families demonstrate resilience and achieve a good fit between the needs of the child with ASD and the needs of the other family members $[14,15]$. Various factors, including social support, the characteristics of the child with ASD, coping strategies and the perception of the problem may be involved in the family's adaptation to ASD and could explain the differences in degree of resilience. Social support (both formal and informal) appears to be a protective factor that relieves parental stress [16-19] and increases personal well-being and family quality of life [20-22]. With regard to the characteristics of children with ASD that relate to family stress, many studies suggest that behaviour 
problems are the main predictor of parental stress rather than the severity of the disorder [23-28]. Parents' coping strategies also prove relevant. Parents who adopt coping strategies of active avoidance (denial, distraction and guilt) report more stress than do those who adopt positive and problem-focused strategies [29-32]. Parents' perceptions of the problem and how they define for themselves the state of their lives also appear to be significant predictors of parents' adaptation. A negative perception of the situation as a catastrophe and feelings of guilt about having caused their child's problems are main predictors of stress for parents of children with intellectual disabilities [33] and mothers with children with ASD [34], whereas positive perceptions or definitions of the situation as manageable, understandable and meaningful seem to protect families from stress and improve their welfare [7, 10, 22, 31, 35, 36].

However, very little is known about the nature and impact of positive perceptions of the situation, because of the dominance of research focused on the negative consequences of ASD. The positive orientation of research on the impact of disability on families with children with ASD and the study of the factors that explain parents' psychological well-being are very new and are progressing only slowly.

A review of the studies on this subject suggests that most research on the situation of parents of children with intellectual disabilities has focused on the analysis of the negative aspects (such as stress, anxiety or depression) and possible related factors [37, 38]. This negative perspective is even more evident in research focused on parents of children with ASD [39]. The idea that caring for a disabled child may have a positive influence on parents and families is not incorporated into the dominant trend in research.

Helf and Glidden [37] conducted a review of published research (between 1970 and 1990) on the adaptation of families of children with intellectual disabilities. Independent judges rated the degree of negativity or positivity reflected in the approach, method and discussion of research. They considered any reference to benefits the family or any of its members had experienced as a result of having a child with disabilities as positivity. Indicating that the family or its members had suffered negative consequences such as anxiety, depression, frustration, loss, illness, neuroticism, stress and others was considered an expression of negativity, particularly when these references were not balanced by the inclusion of positive concepts or reactions such as adequate coping, family strength, positive adjustment, recovery or reward. The study concluded that although there has been some decrease in the negativity in the study of family adjustment over the past 20 years of research (e.g., terms such as "disaster" or "permanent damage" present in the findings of studies in 1970s disappear in studies of 1980s and 1990s), this decrease has not been accompanied by a concomitant increase in positivity. The negative approach in studies on adjustment of families with a member with intellectual disabilities still dominated in the 1990s. According to Helfin and Glidden, "In the overwhelming majority of the articles reviewed, the authors failed to mention any positive outcomes of having a child with a developmental disability" [37, p. 461].

As these authors point out in the introduction to their work [37], and others [14, 40] also assume, various reasons may explain the predominance of studying the negative effects of 
having a child with a developmental disability. The influence of researchers with a clinical orientation whose fundamental experience is related to families with difficulties who look for their assistance, coupled with the challenges of applied research that must evaluate and justify an investment in resources and specific supports for these families, is strong. All of these reasons are honest and understandable, and the results of these studies have certainly provided great help in the form of psychological interventions and support for these families; however, these lines of research have also had some less-than-positive effects.

Research paradigms and interventions both reflect and influence each other. If we only focus on risks and problems and do not formulate hypotheses about family strengths and if we do not develop sensitive instruments for measuring positive experiences of families, we will hardly detect the existence of these strengths. As Antonovsky [40] stated over 20 years ago, if our research questions are formulated negatively and only ask about the negative, we are not very likely to find positive answers.

When research provides an opportunity to make the positive aspects of these situations manifest, those positive aspects become clear. Parents of children with disabilities do not dwell only on difficulties of caring for their children with special needs, but they also speak of the positive impact that having a child with a disability has on their personal growth and family cohesion [14, 41-48].

As Hastings and Taunt [42] reported in their review of research on positive perceptions of disability in the family, one of the first and most relevant documents in this regard is the report by Mullins [49]. Mullins analysed the content of 60 books written by parents of children with different disabilities. He found that parents report that their child's disability involves both strong demands and stress and enrichment and expansion of the meaning of their lives. These conclusions are borne out by a further analysis of texts produced by parents of children with disabilities by Hornby [50].

One of the most important studies on the positive contributions of children with disabilities to the family was conducted by Behr, Murphy and Summers [51]. This research was the basis for the construction of the four scales that make up the Kansas Inventory of Parental Perceptions (KIPP), which includes the specific assessment of positive contributions (Positive Contribution Survey). A qualitative analysis of interviews with 28 families led the researchers to generate a database of 206 items related to the perception of positive contributions that they pooled into 16 categories and five factors. A validation study with 1,262 families with disabled children showed new factors that were not identified in the previous phase. Thus, the Positive Contributions scale was formed, comprising 52 items corresponding to eight dimensions. Positive contributions were defined as a) learning through experience with special problems in life; b) happiness and fulfilment; c) personal strength and family closeness; d) understanding life's purposes; e) personal growth and maturity; f) awareness of future issues; g) expanded social network; g) career or job growth; and $\mathrm{h}$ ) pride and cooperation. In a subsequent study that factor analysed this scale [52], these dimensions were grouped into three distinct factors of positive contributions that 
have become a benchmark for future research: 1) happiness and fulfilment, 2) strength and family closeness, and 3) personal growth and maturity.

Kausar, Jevne and Sobsey [44] conducted a qualitative study of interviews with 19 parents of children with developmental disorders. Most parents reported that accompanying their disabled child throughout their life became a positive and empowering experience for their own lives. Parents reported that the birth of their child with disabilities led them to redefine their role as parents, giving them a new sense of strength and meaning. They also reported that having a positive approach (e.g., addressing their child's achievements and abilities rather than disabilities) increased their hope and determination to seek and find resources and solutions to better meet the needs of their child. The initial experience was described as a frustrating blow, but parents also described how, over time, this experience evolves into a fortress of personal growth and a new meaning of life. Hope appeared linked to a realistic acceptance of the conditions of their disabled child.

These findings about the positive evolution of parents in their perception of the impact of disability on themselves and their family are reaffirmed in the results of a longitudinal study [48]. This study found that while positive perceptions appeared earlier in mothers than in fathers, both parents converged over time in recognition of the positive impact of childhood disability on family life. Additionally, the study of Bayat [14] on the resilience of families with children with autism reported a positive evolution among most parents. This study suggested that a positive change of perspective occurs among parents two years after receiving their child's diagnosis of autism. This change makes them recognise within themselves a new sense of life and makes them more aware of difficulties and differences, stronger and more patient, and more appreciative of small pleasures in their life. The stories of parents in this study further demonstrate that they consider their child with disabilities to have been a source of cohesion and family unity.

This transformation of initial negative reactions into feelings of acceptance and strength and the joy and satisfaction that accompany witnessing their child's accomplishments [43] have been shown in other studies to support parents for the exercise of their role as caregivers Hastings et al. [52] found that positive perceptions of mothers of children with intellectual disabilities were associated with a restructuring of their coping strategies. The authors concluded that the perception of positive contributions can functions as a mechanism to cope with stress and the demands of raising a child with intellectual disabilities. Werner and Shulman [53] reported that giving a positive meaning to the care that parents give to their children, along with self-esteem and psychosocial support, plays a moderating role in the effect of the stigma of disability on psychological well-being for mothers of children with intellectual disability.

Although the findings are still scarce, the few studies we could find on the role of the perception of positive contributions to the psychological adaptation of parents of children with ASD also present suggestive evidence of the protective role of positive perceptions.

Kayfith, Gragg and Orr [54] analysed the relationship between positive experiences and parental stress in 23 pairs of mothers and fathers with school-aged children with ASD. 
While mothers reported more positive perceptions than fathers, these perceptions were negatively related to stress for both mothers and fathers. Data suggesting greater perceived positive contributions among mothers also appeared in a study using a sample from the Spanish population (24 fathers and 33 mothers of children with ASD) [55]. This study reported a negative relationship between perceived positive contributions and anxiety in mothers. Mothers who perceived more positive contributions of their child with ASD had lower levels of anxiety than did mothers who reported fewer perceived positive contributions.

Hastings et al. [56] attempted to identify possible predictors of perceived positive contributions in 41 pairs of parents of preschool children with autism. Their results indicated that mothers reported greater perceived positive contributions than fathers, and none of the characteristics of children evaluated in the study (symptoms of autism, behaviour problems and adaptive behaviours) proved to be a significant predictor of perceptions of positive contributions in fathers or mothers.

In summary, review of the literature allows us to state that research on the positive aspects of living with a child with intellectual disabilities in the family is still in the minority compared to the predominance of research focusing on the negative impact of disabilities. This shortage is even more striking in the case of specific studies on the impact of ASD and points to significant gaps in our knowledge about the role that positive contributions can play in supporting the psychological adjustment and emotional well-being of parents who face the challenge of living with a child with autism.

Another feature of the research in this area is that most of the studies are based on the responses of mothers, both because of mothers' greater availability and because mothers are often assumed to be the primary caregiver for children with disabilities [57]. While we accept that this assumption might be largely true, it is also necessary to note that fathers are generally more involved in raising their children in recent years than they were in previous generations. Many studies found that mothers have higher levels of stress than fathers [3, 58-61], but some recent studies have detected comparable levels of anxiety [30] and no differences in family quality of life $[62,63]$ among mothers and fathers of children with intellectual disabilities.

We consider it important to include fathers as participants in studies on the impact of ASD in the family and recommend that they be represented with appropriately sized samples. As noted by other authors [64], possible discrepancies in the results from different studies comparing the psychological adjustment of mothers and fathers may be related not only to the historical timing of the research but also to methodological variability. In most comparative research, the number of fathers in the study is usually very small, both in absolute terms and in relative terms compared with the number of mothers.

Research on factors related to the psychological well-being of parents (mothers and fathers) who face the challenge of caring for a child with developmental disabilities is doubly important. A better understanding of the factors related to psychological well-being among parents would allow us to design guidelines for psychological support for families and 
orientation guidelines for the different professionals involved in the care of the child. Parents themselves are worthy of the best and most effective psychological support that professionals can provide to promote parents' quality of life and well-being. Research has shown that parents can obtain significant benefit from psychological support to face the challenge of caring for their child with special needs [65-70]. It is also important to remember that the psychological well-being of parents affects the exercise of their parental role and, therefore, contributes to conditions that support the child's development and welfare [71, 72].

This review allows us to justify the pertinence of a study with the primary aim of analysing the relationship between parents' perceived positive contributions of raising a child with ASD and their psychological well-being and perception of family quality of life. The complexity of parents' psychological adaptation processes leads us to propose a complex design that include other variables to obtain the most comprehensive information about possible intervening factors, the relationship among these factors, and the relative position that positive contributions could have on predictive models of parental well-being. An ex post facto design was applied with a wide sample of parents of children diagnosed with ASD (127 mothers and 90 fathers) and the following study variables:

- Predictor variables: age of the child with ASD, behaviour problems, family income, parents' coping strategies, social support and perception of positive contributions

- Criterion variables: parents' psychological well-being and family quality of life.

Considering the results of the research reviewed above, the following hypotheses are formulated:

1. We expect some differences between mothers and fathers. Mothers will have higher levels of perceived positive contributions than fathers.

2. The perception of positive contributions will be related to psychological well-being and perceived family quality of life among the parents in the study. Higher levels of perceived positive contributions would correspond with higher levels of psychological well-being and family quality of life.

3. The perception of positive contributions will be a relevant predictor of the two criterion variables: psychological well-being and family quality of life.

\section{Method}

\subsection{Participants}

The sample used this research was composed of 217 parents of children diagnosed with ASD (127 mothers and 90 fathers). All of the parents spoke Spanish as their primary language. Participation was voluntary and kept confidential. The data presented in Table 1 indicate that mothers and fathers were similar in age, marital status and educational level. 


\begin{tabular}{|c|c|c|}
\hline & $\%(n)$ & $\begin{array}{l}\text { Mean } \\
\text { (Standard Deviation) }\end{array}$ \\
\hline \multicolumn{3}{|l|}{ Mothers $(n=127)$} \\
\hline Age (years) range 28-73 & & $44.03(8.5)$ \\
\hline \multicolumn{3}{|l|}{ Education level } \\
\hline Primary school & $18.9(24)$ & \\
\hline Secondary school & $29.9(38)$ & \\
\hline University & $51.2(65)$ & \\
\hline \multicolumn{3}{|l|}{ Marital status } \\
\hline Married & $88.2(112)$ & \\
\hline Stabled couple & $3.1(4)$ & \\
\hline Divorced & $5.5(7)$ & \\
\hline Windowed & $3.1(4)$ & \\
\hline \multicolumn{3}{|l|}{ Employment status } \\
\hline Unemployed & $43.3(55)$ & \\
\hline Employed & $53.8(67)$ & \\
\hline Retired & $3.9(5)$ & \\
\hline \multicolumn{3}{|l|}{ Fathers $(n=90)$} \\
\hline Age (years) range 32-78 & & $46.05(9.1)$ \\
\hline \multicolumn{3}{|l|}{ Education level } \\
\hline Primary school & $17.8(16)$ & \\
\hline Secondary school & $34.4(31)$ & \\
\hline University & $47.8(43)$ & \\
\hline \multicolumn{3}{|l|}{ Marital status } \\
\hline Married & $94.4(85)$ & \\
\hline Stable couple & $2.2(2)$ & \\
\hline Divorced & $3.3(3)$ & \\
\hline \multicolumn{3}{|l|}{ Employment status } \\
\hline Unemployed & $2.2(2)$ & \\
\hline Employed & $89.0(81)$ & \\
\hline Retired & $7.8(7)$ & \\
\hline
\end{tabular}

Table 1. Demographic information for parents

A significant difference appeared in employment (chi square $=54.89, p=0.01$ ), with $54 \%$ of the mothers and $89 \%$ of the fathers gainfully employed. Data on family composition with the frequency distribution according to number of members and household income are presented in Table 2. 


\begin{tabular}{ll}
\hline Families $(\mathbf{n}=\mathbf{1 3 7})$ & $\%(\mathbf{n})$ \\
\hline Family composition & \\
\hline 2 members & $4.4(6)$ \\
3 members & $25.5(35)$ \\
4 members & $51.8(71)$ \\
5 members & $15.6(20)$ \\
6 members or more & $3.7(5)$ \\
\hline Family incomes & \\
\hline$<500$ euros & $10.9(15)$ \\
$500-850$ euros & $30.7(42)$ \\
$850-1200$ euros & $29.2(40)$ \\
$1200-1800$ euros & $18.2(25)$ \\
$1800-2000$ euros & $2.9(4)$ \\
$>2000$ euros & $8.0(11)$ \\
\hline
\end{tabular}

Table 2. Family composition and family income

\begin{tabular}{ll}
\hline Individuals with ASD $(\mathbf{n}=\mathbf{1 3 7})$ & \multicolumn{1}{c}{$\%(\mathbf{n})$} \\
\hline Age (years) range 3-37 & \\
Gender & $79.6(109)$ \\
Men & $20.4(28)$ \\
Female & \\
Type ASD & \\
Autistic disorder & $59.9(82)$ \\
Asperger's syndrome & $4.4(6)$ \\
Rett's syndrome & $5.8(8)$ \\
Disintegrative disorder & $1.5(2)$ \\
PDD-NOS & $27.7(38)$ \\
Education centre & \\
Ordinary school & \\
Special-education school & \\
Autism-specific school & $53.1(7)$ \\
Day centre & $38.0(52)$ \\
\hline
\end{tabular}

Note. SD=Standard Deviation; $\mathrm{ASD}=$ Autism Spectrum Disorders

PDD-NOS=Pervasive Developmental Disorder - Not Otherwise Specified

Table 3. Demographic information for individuals with ASD 
With regard to the characteristics of the individuals with ASD ( $\mathrm{N}=137)$, it is important to note (see Table 3) the wide age range (3-37 years); the average of age was $M=11.7$ years, $S D=8.36$; 109 of the individuals with ASD were male and 28 were female. The main category of ASD among participants was Autistic Disorder (82), followed by PDD-NOS (38), Rett's Syndrome (8), Asperger's Syndrome (6) and Disintegrative Disorder (2). The criteria diagnoses correspond to the categories of DSM-IV-TR because the diagnoses were made before publication DSM-V (APA, 2013).

\subsection{Procedure}

Initially, the heads of schools were contacted and informed of the aims of the research through the psychologist responsible for the school counselling in the case of ordinary schools and through the Spanish Professional Association of Autism in the case of specific centres. Parents received a letter inviting them to participate in the study. Further instructions were sent with the questionnaires to the voluntary participants. Instructions highlighted the confidential nature of the data, the participants' right to abandon the research if desired and the requirement that questionnaires be completed individually, without discussion with their spouse. We relied on a non-probability sampling based on schools' accessibility to the researcher and individuals' availability for participation (convenience sample). Parents participated by individually completing a set of questionnaires that they received either through the school or by e-mail, depending on their preference. A total of 217 parents (127 mothers and 90 fathers) completed the questionnaires.

\subsection{Measures}

Demographic information describing the parents, individuals with ASD and families was obtained through a brief questionnaire designed by the research team. Six questionnaires administered in Spanish evaluated the study variables. Two questionnaires-the Brief Psychological Well-being and the Family Quality of Life Scale-were previously adapted for Spanish by other authors. We translated the following measures into Spanish: the Behaviour Problems Inventory, the Checklist of Support for Parents of the Handicapped, the Positive Contributions Scale and the Brief Coping Orientation of Problems Experienced. We adopted the backtranslation technique to ensure translation accuracy. Two bilingual experts were invited to translate the Spanish versions back to English to correct differences between the two versions.

The Behaviour Problems Inventory (BPI; [73]), a 52-item scale, was used to assess the behaviour problems of individuals with ASD. Each item is scored on a 4-point severity scale ranging from 0 (no problem) to 3 (a severe problem). The BPI has three subscales: self-injurious, stereotyped and aggressive/destructive behaviour. The BPI has been found to be a reliable and valid rating instrument for behaviour problems in individuals with mental retardation and developmental disabilities [73]. The reliability in the original scale is high, with a Cronbach's alpha of.83 for the total scale. The internal consistency of the total scale in the present study was also high, with $\alpha=.89$. 
The Checklist of Supports for Parents of the Handicapped (CSPH; [74]) was used to evaluate the social support available to parents caring for a child with ASD. It is a 23-item rating scale that uses a 5-point item scale ranging from 0 (nothing useful) to 4 (very useful). The total score of the measure was used in this study. There is no information regarding the internal consistency of the original scale, but in the present study, Cronbach's alpha was.82.

The Positive Contribution Scale of the Kansas Inventory of Parental Perceptions (KIPP; [51]) was chosen to evaluate the positive feelings of parents towards the child with ASD. The KIPP is a 50 -item rating scale that ranges from 1 (strongly disagree) to 4 (strongly agree). Higher scores are associated with greater awareness of the positive perceptions. We also used measures of three subscales: a) source of happiness and fulfilment subscale (six items) to represent positive feelings towards the child; b) source of personal growth and maturity subscale (seven items) to indicate positive impact upon the respondent; and c) source of strength and family closeness (seven items) to represent the positive impact upon the family. The alpha reliability for the original Positive Contribution Scale was.80. For the subscales, the alpha reliability ranged from. 84 and.86, indicating good psychometric characteristics. In the present study, Cronbach's alpha for the total scale was.91, and for the subscales, the alpha ranged from.68 to.81.

The Brief Coping Orientation of Problems Experienced (Brief-COPE; [75]; adapted to Spanish by [76]) was used to obtain information on coping strategies used by parents raising an individual with ASD. The Brief-COPE has 14 two-item subscales. Each item is rated in terms of how often the responder utilises a particular coping strategy as measured on a 4-point scale, where 0 represents "I have not been doing this at all" and 3 represents "I've been doing this a lot".

To reduce the number of strategies, we performed a principal component factor analysis following the methodology used by Hastings et al. [30]. The results showed that two factors explained $28 \%$ of the variance; the two factors included items from the original Brief-COPE sub-scales. Factor 1, which is named "positive and problem-focused coping strategies", includes thirteen items for active coping, planning, seeking instrumental and emotional social support, positive reframing, and humour (items 2, 5, 7, 10, 12, 14, 15, 17, 18, 19, 21, 23 and 28). Factor 2, which is named "active avoidance coping strategies", includes nine items (items 1, 3 , $6,8,9,16,20(-), 24(-)$ and 26). Only the scores for these two factors were used in the current study. Reliability was good for the total scale $(\alpha=.77)$, positive and problem-focused coping strategies $(\alpha=.79)$, and active avoidance coping strategies $(\alpha=.71)$.

The Brief Psychological Well-being Spanish Version [77] is a brief version of the original Psychological Well-being Scale [78]. It is a 29-item scale with a 4-point item scale ranging from 1 (completely disagree) to 4 (completely agree). The 29 items are organised into six dimensions (self-acceptance, positive relations, autonomy, environmental mastery, purpose in life and personal growth). The measure of psychological well-being used in this study was the total score. The internal consistency of the brief version of the scale in the original study was good $(\alpha=.84)$. In the present study, Cronbach's alpha was.91.

The Family Quality of Life Scale (FQOL [79]; adapted for Spanish by [80] was used to assess parents' satisfaction with their family quality of life. This is a 25 -item scale with five sub-scales (family interaction, emotional well-being, parenting, physical/material well-being and 
disability-related support). This scale has two different response formats: satisfaction and importance. We used the total score of satisfaction format in this study. The items are rated on a 5-point scale ranging from 1 (very dissatisfied) to 5 (very satisfied). Cronbach's alpha for the FQOL subscale rating of satisfaction was.94 in the original study and.95 in this study.

There were no missing values for the total scores of any of the scales. Missing values were limited to specific items of the questionnaires and were not always the same. The rates for all missing data were less than $1 \%$. We applied average values derived from the existing values to fill in missing items. Comparative analysis between mothers and fathers were applied. Bivariate correlations and multiple regression analysis were performed separately for mothers and fathers. Data analysis was conducted using the SPSS 15 Program. The G* Power 3.1 program [81] was used to calculate the effect size.

\section{Results}

\subsection{Comparative analysis between fathers and mothers}

First, we were interested in exploring the data to know the average values of the variables that made up the study among both fathers and mothers. T-tests were applied to examine whether there were significant differences in the values of the variables between the two groups. The results of the comparisons of mean values are shown in Table 4.

As shown by the data in the table, we did not find significant differences between fathers and mothers in the perception of the severity of the behaviour problems presented by children with ASD. The same pattern was found with the social support total score and subscale scores (informal, formal, and informational). None of the criterion variables (psychological wellbeing and family quality of life) was found to be significantly different between the groups.

The study variables that showed significant differences between fathers and mothers were the positive contributions and coping strategies. In relation to the positive contributions that the child of ASD brings to the family, the data indicated that mothers perceive a higher amount of positive contributions than fathers $(t(1,215)=-2.97, p=.003 ; M=134.94, M=126.76$, respectively). The same results were found with the subscale of strength and family closeness ( $t$ ( 1 , 215)=-3.18; $\mathrm{p}=.002 ; M=21.84$ for mothers, $M=20.20$ for fathers). The effect sizes of the differences were Cohen's $d=.41$, and.44 for the total scale and subscale scores, respectively.

With regard to coping strategies, t-tests showed that mothers reported higher use of both strategies: positive and problem-focused coping strategies $(t(1,215)=-3.50 ; p=.001 ; M=17.76$ for mothers, $M=15.14$ for fathers; Cohen's $d=.49)$ and active avoidance coping $(t(1,215)=-3.18$; $p=$. $05 ; M=3.67$ for mothers, $M=2.87$ for fathers; Cohen's $d=.27$ ).

Another aspect of active avoidance strategies to note is that the average value obtained in both groups is very small ( $M=3.67$ for mothers, $M=2.87$ for fathers) because the potential range that this variable can reach is $0-21$. These data indicate the limited use of this type of strategy for dealing with situations that arise in everyday life. 


\begin{tabular}{|c|c|c|c|c|c|c|}
\hline & Fath & $\mathbf{s}(n=90)$ & Mothe & $(n=127)$ & & \\
\hline Variables & Mean & $S D$ & Mean & $S D$ & $t(1,215)$ & $\begin{array}{l}\text { Effect size } \\
\text { (Cohen' d) }\end{array}$ \\
\hline Behaviour problems & 18.79 & 15.16 & 18.65 & 13.89 & .68 & \\
\hline Social support & 49.03 & 15.22 & 49.80 & 14.81 & -.37 & \\
\hline Informal support & 20.48 & 6.32 & 19.07 & 6.80 & 1.54 & \\
\hline Formal support & 17.80 & 6.73 & 18.35 & 6.73 & -.60 & \\
\hline Informational support & 10.76 & 5.97 & 12.37 & 6.51 & -1.86 & \\
\hline Positive contributions & 126.76 & 20.47 & 134.94 & 19.53 & $-2.97^{\star *}$ & .41 \\
\hline Happiness and fulfilment & 17.53 & 3.69 & 18.35 & 3.60 & -1.64 & \\
\hline Personal growth and maturity & 17.69 & 4.60 & 18.54 & 4.56 & -1.36 & \\
\hline Strength and family closeness & 20.20 & 4.13 & 21.84 & 3.43 & $-3.18^{* *}$ & .44 \\
\hline $\begin{array}{l}\text { Positive and problem-focused } \\
\text { coping }\end{array}$ & 15.14 & 4.96 & 17.76 & 5.71 & $-3.50^{* *}$ & .49 \\
\hline Active avoidance coping & 2.87 & 2.76 & 3.67 & 3.07 & $-1.97^{\star}$ & .27 \\
\hline Psychological well-being & 124.34 & 22.52 & 122.63 & 18.91 & .61 & \\
\hline Family quality of life & 85.97 & 18.12 & 87.60 & 15.75 & -.71 & \\
\hline
\end{tabular}

Table 4. Results of the comparisons of fathers and mothers' mean values on study variables

\subsection{Correlations}

Pearson correlations were used to explore bivariate associations between all of the variables considered. Correlations were calculated separately for fathers and mothers (see Tables 5a and $5 b$, respectively). The correlations results are described below.

The table data show that psychological well-being has a significant positive relationship with family quality of life in both parents ( $r=.49$ for fathers; $r=.54$ for mothers). For both parents, psychological well-being was negatively associated with behaviour problems ( $r=-.38$ for fathers; $r=-.20$ for mothers) and with active avoidance coping ( $r=-.51$ for fathers; $r=-.33$ for mothers), and positively correlated with positive contributions ( $r=.27$ for fathers; $r=.37$ for mothers). For fathers, we also found a positive relationship with family income $(r=.21)$. In the case of mothers, psychological well-being was positively correlated with social support $(r=.24)$ and positive and problem-focused coping strategies $(r=.19)$.

For fathers and mothers, the family quality of life was negatively associated with behaviour problems ( $r=-.29, r=-.21$, respectively) and active avoidance coping $(r=-.23, r=-.33$, respectively). Additionally, for both parents, family quality of life was positively associated with social support ( $r=.23, r=.23$, respectively). Only in the case of mothers was family quality of life 


\begin{tabular}{|c|c|c|c|c|c|c|c|c|c|}
\hline & 1 & 2 & 3 & 4 & 5 & 6 & 7 & 8 & 9 \\
\hline 1. Age of individuals with ASD & --- & & & & & & & & \\
\hline 2. Educational level & -.02 & - & & & & & & & \\
\hline 3. Family income & .17 & $.29^{* *}$ & - & & & & & & \\
\hline 4. Behaviour problems & -.11 & -.11 & -.17 & - & & & & & \\
\hline 5. Social support & -.03 & -.02 & -.09 & -.02 & - & & & & \\
\hline 6. Positive contributions & -.04 & .01 & $.24^{*}$ & $-.22^{*}$ & $.25^{*}$ & - & & & \\
\hline $\begin{array}{l}\text { 7. Positive and problem-focused } \\
\text { coping }\end{array}$ & $-.28^{*}$ & $.22^{*}$ & .12 & .11 & .17 & .19 & - & & \\
\hline 8. Active avoidance coping & -.02 & -.15 & -.16 & $.33^{\star \star}$ & -.07 & -.01 & .10 & - & \\
\hline 9. Psychological well-being & .06 & .13 & $.21^{*}$ & $-.38^{* *}$ & .08 & $.27^{*}$ & .02 & $-.51^{* *}$ & - \\
\hline 10 Family quality of life & .11 & .15 & .03 & $-.29 * *$ & $.23^{*}$ & .20 & -.04 & $-.23^{*}$ & $.49^{* *}$ \\
\hline \multicolumn{10}{|c|}{ (a) } \\
\hline & 1 & 2 & 3 & 4 & 5 & 6 & 7 & 8 & 9 \\
\hline 1. Age of individuals with ASD & - & & & & & & & & \\
\hline 2. Educational level & $-.18^{*}$ & - & & & & & & & \\
\hline 3. Family income & .12 & $.26^{* *}$ & - & & & & & & \\
\hline 4. Behaviour problems & -.12 & -.12 & $-.22^{*}$ & - & & & & & \\
\hline 5. Social support & .03 & -.08 & -.03 & -.08 & - & & & & \\
\hline 6. Positive contributions & -.12 & -.14 & -.01 & -.01 & $.24^{*}$ & - & & & \\
\hline $\begin{array}{l}\text { 7. Positive and problem-focused } \\
\text { coping }\end{array}$ & -.13 & .01 & -.07 & $.22 *$ & .11 & $.25^{\star *}$ & - & & \\
\hline 8. Active avoidance coping & .05 & -.11 & -.03 & $.23^{* *}$ & -.09 & -.06 & .10 & - & \\
\hline 9. Psychological well-being & -.06 & .12 & .16 & $-.20^{*}$ & $.24^{\star *}$ & $.37^{\star *}$ & $.19^{*}$ & $-.38^{* *}$ & - \\
\hline 10. Family quality of life & -.09 & .06 & .05 & $-.21^{*}$ & $.23^{* *}$ & $.31^{* *}$ & $.21 *$ & $-.33^{* *}$ & $.54^{* *}$ \\
\hline
\end{tabular}

** $P<0.01, * P<0.05$

Table 5. (a) Pearson correlation coefficients for total measures of study variables in fathers; (b) Pearson correlation coefficients for total measures of study variables in mothers

positively associated with positive contributions $(r=.31)$ and positive and problem-focused coping $(r=.21)$.

Next, we describe the relationship between predictor variables. Educational level was positively associated with family income ( $r=.29$ for fathers; $r=.26$ for mothers), and social support was positively correlated with positive contributions ( $r=.25$ for fathers; $r=.24$ for mothers). Only in mothers, the perception of severity of child's behaviour problems were negatively associated with family income $(r=-.22)$ and positively associated with the two types of coping ( $r=.22$ for positive and problem-focused coping; $r=.23$ for active avoidance coping). In the case of fathers, behaviour problems were negatively correlated with positive contributions ( $r=-.22)$, and positive contributions were positively associated with family income $(r=.24)$. 
We performed a more detailed analysis of the relationship between positive contributions (total and subscales) and the other variables included in the study. Correlations were calculated separately for fathers and mothers. The results are presented in Tables $6 a$ and $6 b$, respectively.

\begin{tabular}{lcccc}
\hline & $\begin{array}{c}\text { Total positive } \\
\text { contributions }\end{array}$ & $\begin{array}{c}\text { Happiness and } \\
\text { fulfilment }\end{array}$ & $\begin{array}{c}\text { Personal growth and } \\
\text { maturity }\end{array}$ & $\begin{array}{c}\text { Strength and family } \\
\text { closeness }\end{array}$ \\
\hline Age of individuals with ASD & -.04 & $-.31^{* *}$ & -.06 & -.03 \\
Educational level & .01 & -.06 & -.12 & -.02 \\
Family income & $.24^{*}$ & $.23^{*}$ & $.25^{\star}$ & $.23^{*}$ \\
Behaviour problems & $-.22^{*}$ & -.20 & -.07 & -.12 \\
Social support & $.25^{*}$ & .13 & .06 & .19 \\
Positive and problem-focused & .19 & .20 & .17 & $.24^{*}$ \\
coping & -.01 & $-.23^{*}$ & -.07 & -.06 \\
Active avoidance coping & $.27^{*}$ & $.22^{*}$ & .12 & $.29^{* *}$ \\
Psychological well-being & .20 & .11 & -.04 & $.23^{*}$ \\
Family quality of life & & $(a)$ & \\
\hline
\end{tabular}

(a)

\begin{tabular}{lcccc}
\hline & $\begin{array}{c}\text { Total positive } \\
\text { contributions }\end{array}$ & $\begin{array}{c}\text { Happiness and } \\
\text { fulfilment }\end{array}$ & $\begin{array}{c}\text { Personal growth and } \\
\text { maturity }\end{array}$ & $\begin{array}{c}\text { Strength and family } \\
\text { closeness }\end{array}$ \\
\hline Age of individuals with ASD & -.12 & $-.32^{* *}$ & -.02 & -.01 \\
Educational level & -.13 & -.04 & $-.26^{* *}$ & -.05 \\
Family income & -.01 & -.03 & -.98 & .05 \\
Behaviour problems & -.01 & -.14 & .07 & .04 \\
Social support & $.24^{* *}$ & .11 & .13 & .09 \\
Positive and problem-focused & $.25^{* *}$ & $.18^{*}$ & $.22^{*}$ & $.25^{* *}$ \\
coping & -.06 & $-.18^{*}$ & -0.12 & -.16 \\
Active avoidance coping & $.37^{* *}$ & $.38^{* *}$ & $.18^{*}$ & $.32^{* *}$ \\
Psychological well-being & $.31^{* *}$ & $.35^{* *}$ & .16 & $.29^{* *}$ \\
Family quality of life & & & & \\
\hline
\end{tabular}

(b)

${ }^{* *} P<0.01,{ }^{*} P<0.05$

Table 6. (a) Pearson correlation coefficients between positive contributions (total and subscales) and other study variables among fathers; (b) Pearson correlation coefficients between positive contributions (total and subscales) and other study variables among mothers

The correlations involving the total score on the positive contributions scale has already been described; here we describe only the findings related to the subscales. For both parents, the happiness and fulfilment subscale was positively correlated with psychological well-being $(r=$. 
22 for fathers; $r=.38$ for mothers), and negatively associated with age of the children ( $r=-.31$ for fathers; $r=-.32$ for mothers) and active avoidance coping ( $r=-.23$ for fathers; $r=-.18$ for mothers).

The strength and family closeness subscale was positively associated with three variables: psychological well-being ( $r=.29$ for fathers; $r=.32$ for mothers), family quality of life ( $r=.23$ for fathers; $r=.29$ for mothers) and positive and problem-focused coping ( $r=.24$ for fathers; $r=.25$ for mothers).

In the case of fathers, family income was positively correlated with the three subscales $(r=.23$ for happiness and fulfilment; $r=.25$ personal growth and maturity; $r=.23$ for strength and family closeness). In the case of mothers, two subscales were positively associated with positive and problem-focused coping ( $r=.18$ for happiness and fulfilment; $r=.22$ for personal growth and maturity), psychological well-being ( $r=.38$ for happiness and fulfilment; $r=.18$ for personal growth and maturity), and family quality of life ( $r=.35$ for happiness and fulfilment; $r=.29$ for strength and family closeness).

Having explored the correlation matrix of the variables, we next examined which variables predict psychological well-being and family quality of life. We performed a multiple regression analysis, as described below.

\subsection{Regression}

A stepwise forward selection multiple regression analysis was run to examine the predictor variables of psychological well-being and family quality of life. The analysis was carried out separately for fathers and mothers. We considered the age of children with ASD, behaviour problems, family income, social support, positive contributions and coping strategies (active avoidance coping and positive and problem-focused coping) as potential predictor variables. The null hypotheses tested were that multiple $R^{2}$ was equal to 0 and that the regression coefficients were equal to 0 . The data were screened for violation of assumptions prior to analysis.

The results of the multiple regression analysis for psychological well-being are presented in Table 7 . We used the adjusted $R^{2}$ index, which indicates the percentage of variation in the dependent variable explained after adjusting for sample size and the number of predictors.

The active avoidance coping strategies measure was the main explicative variable in the models for both mothers and fathers, accounting for a significant amount of the variance in psychological well-being ( $\Delta$ adjusted $R^{2}=.24$ for fathers and.14 for mothers). Specifically, higher levels of active avoidance coping strategies predicted lower levels of psychological well-being ( $\beta=-.50, p<.001$ for fathers and $\beta=-.38, p<.001$ for mothers). Positive contributions also accounted for a significant amount of the variance in psychological well-being ( $\Delta$ adjusted $R^{2}=.07$ for fathers and.11 for mothers). In this case, higher levels of positive contributions predicted higher levels of psychological well-being ( $\beta=.26, p=.004$ for fathers and $\beta=.35, p<.001$ for mothers). The regression model included a third predictive variable in the case of fathers, indicating that higher behaviour problems predicted lower fathers' psychological well-being ( $\beta=-.19, p=.049)$. The total adjusted $R^{2=} .33$ for the fathers' model indicated that these three variables accounted 


\begin{tabular}{lccccc}
\hline \multicolumn{1}{c}{ Variables } & adjusted $\mathbf{R}^{2}$ & $\boldsymbol{\Delta} \mathbf{R}^{2}$ & $\begin{array}{c}\text { Degrees of } \\
\text { freedom }\end{array}$ & $\boldsymbol{F}$ & $\boldsymbol{\beta}$ \\
\hline Active avoidance coping & .24 & .24 & $(1,87)$ & $29.32^{* *}$ & $-.50^{* *}$ \\
Positive contribution & .31 & .07 & $(1,86)$ & $20.47^{* *}$ & $.26^{* *}$ \\
Behaviour problems & .33 & .02 & $(1,85)$ & $15.45^{* *}$ & $-.19^{*}$ \\
\hline \multicolumn{1}{c}{ Variables } & adjusted $\boldsymbol{R}^{2}$ & $\boldsymbol{\Delta} \mathbf{R}^{2}$ & Degrees of & $\boldsymbol{F}$ & $\boldsymbol{\beta}$ \\
\hline freedom & .14 & $(1,125)$ & $20.71^{* *}$ & $-.38^{* *}$ \\
\hline Pctive avoidance coping & .14 & .11 & $(1,124)$ & $22.00^{* *}$ & $.35^{* *}$ \\
\hline
\end{tabular}

(b)

${ }^{* *} p<.01 ;{ }^{*} p<.05$

Table 7. (a) Regression analysis predicting psychological well-being in fathers' (b) Regression analysis predicting psychological well-being in mothers

for approximately $33 \%$ of the variation in psychological well-being among fathers. Interpreted according to [82], this value suggests a large effect size $\left({ }^{2}=49\right)$. In the case of mothers, the multiple adjusted $R^{2=} .25\left({ }^{2}=.33\right)$ indicated a medium effect size. Other variables proposed in the analysis such as age of children with ASD, family income, and social support were not included in the models, indicating that these variables do not account for a significant amount of variance in psychological well-being after including active avoidance coping strategies, positive contributions and behaviour problems.

Regression models of family quality of life are presented in Table 8 . The fathers' model includes only behaviour problems and social support as predictor variables, and the total adjusted $R^{2=}$. $11\left({ }^{2}=12\right)$ indicates a small effect size. Higher behaviour problems predicted lower perceived family quality of life $(\beta=-.28, p=.007)$, and higher levels of social support predicted higher levels of family quality of life $(\beta=.23, p=.027)$ among fathers.

In mothers, the regression model was more complex, with four predictors that could predict $23 \%$ of the variance of family quality of life (adjusted $R^{2=} .23 ;{ }^{2=} .30$ ), which suggests a medium effect size. The active avoidance coping strategies measure was the main variable explaining the variance in family quality of life among mothers ( $\Delta$ adjusted $R^{2}=.11$ ). Behaviour problems also appeared as a predictor ( $\Delta$ adjusted $R^{2}=.02$ ). Higher levels of active avoidance coping strategies and behaviour problems predicted lower levels of family quality of life $(\beta=-.33, p<$. 001 and $\beta=-.18, p=.027$, respectively). Positive contributions and positive and problem-focused coping strategies accounted for a significant amount of the variance in mothers' reported family quality of life ( $\Delta$ adjusted $R^{2}=.04, \Delta$ adjusted $R^{2}=.05$, respectively). Higher levels of positive contributions and positive and problem-focused coping strategies predicted higher levels of mothers' reported family quality of life $(\beta=.29, p=.004$ and $\beta=.18, p=.011$, respectively). 


\begin{tabular}{lccccc}
\hline \multicolumn{1}{c}{ Variables } & adjusted $\boldsymbol{R}^{2}$ & $\boldsymbol{\Delta} \mathbf{R}^{2}$ & $\begin{array}{c}\text { Degrees of } \\
\text { freedom }\end{array}$ & $\boldsymbol{F}$ & $\boldsymbol{\beta}$ \\
\hline Behaviour problems & .07 & .07 & $(1,87)$ & $7.63^{* *}$ & $-.28^{\star *}$ \\
Social support & .11 & .04 & $(1,86)$ & $6.53^{\star *}$ & $.23^{* *}$ \\
\hline
\end{tabular}

(a)

\begin{tabular}{lccccc}
\hline \multicolumn{1}{c}{ Variables } & adjusted $\boldsymbol{R}^{2}$ & $\boldsymbol{\Delta} \mathbf{R}^{2}$ & $\begin{array}{c}\text { Degrees of } \\
\text { freedom }\end{array}$ & $\boldsymbol{F}$ & $\boldsymbol{\beta}$ \\
\hline Active avoidance coping & .11 & .11 & $(1,125)$ & $15.73^{* *}$ & $-.33^{* *}$ \\
Positive contributions & .16 & .04 & $(1,124)$ & $15.29^{* *}$ & $.29^{* *}$ \\
Positive and problem-focused coping & .21 & .05 & $(1,123)$ & $11.98^{* *}$ & $.18^{*}$ \\
Behaviour problems & .23 & .02 & $(1,122)$ & $10.53^{* *}$ & $-.18^{* *}$ \\
\hline
\end{tabular}

(b)

${ }^{* *} p<.01 ;{ }^{*} p<.05$

Table 8. (a) Regression analysis predicting family quality of life in fathers; (b) Regression analysis predicting family quality of life in mothers

The other variables proposed in the analysis (age of children with ASD and family income) were not included in the models.

\section{Discussion}

We conducted a study with the aim of analysing both the perception of positive contributions of disability in a large sample of Spanish parents with children with ASD and the impact of this positive perception on their well-being. The results confirm the relevance of the perception of positive contributions of disability for both parents and support its role as predictor of psychological well-being and family quality of life. Coping strategies also appear as a relevant factor, in relation to both the parents' well-being and their perception of positive contributions. The results also provide suggestive information on common and specific issues for fathers and mothers.

Comparative analysis of the values reported by fathers and mothers in terms of the different variables of the study inform us that both groups showed similar levels of psychological wellbeing, perceptions of family quality of life and social support. However, the results reported differences in coping strategies and perceptions of positive contributions, such that mothers had higher values than fathers. These results are consistent with the hypothesis that differences exist between fathers and mothers on these measures. The finding of greater perceived positive contributions among mothers is consistent with what has been detected in other studies [54-56]. However, providing an explanation for this result is not easy. One could pose an explanatory hypothesis based on gender characteristics, but one hypothesis to consider the 
role of primary caregiver among mothers in most families may be more parsimonious. The role of primary caregiver can generate more everyday strain but may also provide more opportunities to experience personal growth and strength as positive contributions of their disabled child. The significant difference on the outside employment situation of fathers and mothers in our sample ( $89 \%$ and $54 \%$, respectively) is a relevant fact that demonstrates the high probability that mothers were exercising the role of primary caregiver. In addition, this difference in employment status of parents of children with ASD is not unique to our sample and the social environment in which this study is carried out but instead seems to be a fairly widespread reality [83].

The results of the correlation analysis showed a positive relationship between the perception of positive contributions and psychological well-being among both fathers and mothers. That is, parents who perceived more positive contributions of their child's disability had higher levels of psychological well-being. In mothers, it also appeared that a positive relationship existed between perceived positive contributions and the perception of family quality of life. These results support the hypothesis that the positive relationship between perceived positive contributions and the perception of family quality of life exists, but it appeared only in the case of mothers. The positive relationship between positive contributions and psychological wellbeing found in this study is consistent with the results of other studies that found a negative relationship between perceived positive contributions and both paternal stress [54] and maternal anxiety [55] in parents of children with ASD.

It is pertinent to note the relationship between coping strategies and perceived positive contributions. More frequent use of active avoidance coping strategies had a negative relationship with the perception that the condition of their child contributed to their happiness and fulfilment among both fathers and mothers. Meanwhile, positive and problem-focused coping strategies were associated with the perception of positive contributions, particularly in the case of mothers. For fathers, only a positive relationship between positive and problem focused coping strategies and the subscale of strength and family closeness appeared, while in the case of mothers, this relationship was broader. Mothers who reported greater use of positive and problem-focused coping strategies reported also higher levels of perceived contributions not only in relation to the strength and closeness of the family but also in relation to more personal aspects such as happiness and fulfilment and personal growth and maturity.

The bidirectionality of these relationships makes it difficult to know whether the ability to perceive positive contributions has a positive effect on promoting the use of positive and problem-focused coping strategies or whether parents who resort to this type of coping strategy better perceive the positive contributions of their child to their life and the life of their family. It is also possible that a third variable, such as a psychological trait, could explain the covariation of these two factors. In any case, despite the difficulty of clarifying the direction of effects, this finding on the relationship between coping strategies and positive perceptions is important, to the extent that both factors were also expressed as predictors of psychological well-being and the family quality of life reported by parents. Both aspects could become the subject of future work in psychological intervention to support parents with potential mutual benefits and positive effects on parents' well-being. 
Active avoidance coping strategies appeared as the main predictor negatively related to psychological well-being in the regression models, both mothers and fathers. Positive and problem-focused coping strategies appeared as relevant predictor of family quality of life among mothers. This finding is consistent with the results of previous research on parental stress. Research examining the coping strategies used by parents to manage daily situations has demonstrated that parents who adopt active avoidance coping strategies report more stress than parents who adopt positive reframing coping strategies [29,30]. Other studies show that, compared with parents of typically developing children, parents of children with ASD more frequently employ escape-avoidance coping strategies [84-86]. Therefore, it is important to help parents of children with ASD discover and implement positive coping strategies that can replace these avoidance coping strategies.

The results of the regression analyses are also consistent with the fundamental hypothesis of this study on the relevance of the perception of positive contributions as predictor of parental well-being. Another common result for both groups, mothers and fathers, was the detection of perceived positive contributions as the second most important predictor of parents' psychological well-being. The regression models of family quality of life also highlighted the role of positive contributions; however, in this case, this variable only appears as a relevant predictor in the model of mothers. Increases in the perception of positive contributions predicted increases in family quality of life. Inversely, behaviour problems of the child predicted lower family quality of life, both mothers and fathers.

Before considering the implications of the findings of this research, it is convenient to reflect on its limitations. The main limitation to note is the correlational and cross-sectional nature of the design and, therefore, the inability to determine the direction of effects in the relationships between variables. Although we assign and test the possible role of predictor variables when performing regression analysis and although some of the study results are significant and clear, we cannot rule out influences in the other direction. Perceived positive contributions appear in our results to have a predictive in increasing psychological well-being and family quality of life, but we cannot know to what extent the levels of parents' psychological well-being affect their ability to perceive positive contributions of disability. More research, especially longitudinal research, is required to advance knowledge of the direction of these effects.

In addition, it must be noted that this study is based on a sample of Spanish families. We must be aware that there are significant cultural differences in the understanding of disability and the dynamics of families and should therefore be cautious in generalising these results to other cultures.

\section{Conclusions}

Despite its limitations, this study contributes to a better understanding of the factors related to the psychological well-being of parents raising a child with ASD. A better understanding of these factors may guide the design of intervention strategies to promote parents' well-being. The empirical evidence supporting the importance of coping strategies and the perception of the positive contributions of disability for parental psychological well-being and their family 
quality of life suggest the importance of awareness among professionals working with families. Parents of children with ASD are faced with many potential stressful situations. The challenges may change over the course of their children's lifespan. There is not only one pattern of coping that fits well for all of these stressful situations. The results of the current investigation show that active avoidance coping strategies may be maladaptative and may not contribute to parents' well-being. Professional interventions to help parents of children with ASD could include objectives oriented to provide them with a wide repertoire of emotional, cognitive and instrumental positive coping strategies and to develop the flexibility to implement the most appropriate strategy to address the situation at a given time. Moreover, helping parents in their processes of positive transformation, guiding them to pay attention to and learn to appreciate the achievements of their children and helping them discover their own personal and family strengths will contribute to their well-being.

We agree with Patterson [87] in her conclusion that clinicians who believe in the ability of the family to discover their strengths are in a much better position to enhance family resilience and facilitate the adaptive processes needed by the family to restore its functioning after a crisis situation. Believing in the ability of the family to discover their strengths and recognising their success in coping with stressful situations, whether large or small, empowers the family to cope effectively. The importance of paying attention to the positive aspects of the development of children and families it is not solely the responsibility of clinicians. Many professionals in very different roles (psychologists, medical, nurses, social workers and teachers) are involved in accompanying parents in caring for their child with ASD. In each moment of evaluation, monitoring or guidance to parents, professionals' ability to adopt, within their speciality, a perspective not only focused on the problem and the difficulties but also oriented toward the child's achievements and other positive aspects of his or her development and family's functioning can be critical to help parents develop strength and positive experiences.

Over the past few decades, we have been able to incorporate major changes related to the perception of people with disabilities. An increase in sensitivity has led to important legislative changes that recognise and promote rights aimed at improving the quality of life of people with intellectual disabilities and their families. There have been changes that affect aspects as simple as our language, such as changing the disorder-focused expression (e.g., disabled child or autistic child) to a person-focused expression (e.g., child with intellectual disabilities or child with autism or ASD) or changing patient consideration to the active participants, and some decisive other as inclusive education. Considering not only the problem and special needs of the child but also the positive contributions of people with disabilities to their environment, particularly to their family, is a necessary change in both research and practice. This change is just beginning to take hold, and much more work in practice and research is needed.

\section{Author details}

Encarnación Sarriá and Pilar Pozo

Faculty of Psychology, UNED: National University of Distance Education, Madrid, Spain 


\section{References}

[1] American Psyquiatric Association. Diagnostic and Statistical Manual of Mental Disorders, Fifth Edition (DSM-5). Washington, DC: APA; 2013.

[2] Bryson S. Brief Report: Epidemiology of Autism. Journal of Autism and Developmental Disorders 1996;26: 165-167. http://dx.doi.org/10.1007/BF02172005

[3] Hastings RP. Child Behavior Problems and Partner Mental Health as Correlates of Stress in Mothers and Fathers of Children with Autism. Journal of Intellectual Disability Research 2003;47; 231-237. http://dx.doi.org/10.1046/j.1365-2788.2003.00485.x

[4] Sigman M, Capps L. Children with Autism: A developmental Perspective. Cambridge, MA: Harvard University Press; 1997.

[5] Woolfenden S, Sarkozy V, Ridley G, Williams KA. Systematic Review of the Disgnostic Stability of Autism Spectrum Disorder. Research in Autism Spectrum Disorders 2012;6: 345-354. Available from http://prognosismethods.cochrane.org/sites/prognosismethods.cochrane.org/files/uploads/Woolfenden\%202012.pdf (accessed 14 February 2014).

[6] Seguí JD, Ortiz-Tallo M, de Diego Y. Factores Asociados al Estrés del Cuidador Primario de Niños con Autismo: Sobrecarga, Psicopatología y Estado de Salud. Anales de Piscología 2008;24(1): 100-105. http://hdl.handle.net/10201/8145

[7] Belchic JK. Stress, Social Support and Sense of Parenting Competence: A Comparison of Mothers and Fathers of Children with Autism, Down Syndrome and Normal Development across the Family Life Cycle. Dissertation Abstracts International Section. Humanities and Social Sciences 2006;57: 2-4.

[8] Baker-Ericzén MJ, Brookman-Frazee L, Stahmer A. Stress Level and Adaptability in Parents of Toddlers with and without Autism Spectrum Disorders. Research and Practice for Persons with Severe Disabilities 2005;30: 194-204. http://dx.doi.org/ 10.2511/rpsd.30.4.194

[9] Feldman M, McDonal L, Servin L, Stack D, Secco MD, Yu CT. Predictors of Depressive Symptoms in Primary Caregivers of Young Children with or at Risk for Developmental Delay. Journal of Intellectual Disability Research 2007;51: 606-619.

[10] Olsson MB, Hwang CP. Sense of Coherence in Parents of Children with Different Developmental Disabilities. Journal of Intellectual Disability Research 2002;46: 548-559. http://dx.doi.org/10.1046/j.1365-2788.2002.00414.x

[11] Phetrasuwan S. Psychological Adjustment in Mother of Children with Autism Spectrum Disorders. Dissertation Abstracts International: Section B: The Sciences and Engineering 2003;64(11B), 5452.

[12] Pisula E. Parenting Stress in Mothers and Fathers of Children with Autism Spectrum Disorders. In: Mohammadi MR. (ed.) A Comprehensive Book on Autism Spectrum 
Disorders. Rijeka: InTech; 2011. p87-106. Available from: http://www.intechopen.com/books/a-comprehensive-book-on-autism-spectrum-disorders/parentingstress-in-mothers-and-fathers-of-childrenwith-autism-spectrum-disorders (accessed 19 April 2014).

[13] Singer GH. Meta-Analysis of Comparative Studies of Depression in Mothers of Children with and without Developmental Disabilities. American Journal on Mental Retardation 2006;111: 155-169.

[14] Bayat M. Evidence of Resilience in Families of Children with Autism. Journal of Intellectual Disability Research 2007;51: 702-714. http://dx.doi.org/10.1111/j. 1365-2788.2007.00960.x

[15] Gerstein ED, Crnic KA, Blacher J, Baker BL. Resilience and the Course of Daily Parenting Stress in Families of Young Children with Intellectual Disabilities. Journal of Intellectual Disability Research 2009;53: 981-997. http://dx.doi.org/10.1111/j. 1365-2788.2009.01220.x

[16] Ben-zur H, Duvdevany I, Lury L. Associations of Social Support and Hardiness with Mental Health among Mothers of Adult Children with Intellectual Disability. Journal of Intellectual Disability Research 2005;49: 54-62. http://dx.doi.org/10.1111/j. 1365-2788.2005.00662.x

[17] Boyd, B. A. Examining the Relationship between Stress and Lack of Social Support in Mothers of Children with Autism. Focus on Autism and Other Developmental Disabilities 2002;17: 208-215. http://dx.doi.org/10.1177/10883576020170040301

[18] Shu B, Lung F. The Effect of Support Group on the Mental Health and Quality of Life for Mothers with Autistic Children. Journal of Intellectual Disability Research 2005;49: 47-53. http://dx.doi.org/10.1111/j.1365-2788.2005.00661.x

[19] Pozo P, Sarriá E. A Global Model of Stress in Parents of Individuals with Autism Spectrum Disorders (ASD). Anales de Psicología 2014;30(1): 180-191. Available from http://www.redalyc.org/pdf/167/16729452019.pdf (accessed 19 March 2014).

[20] Benson PR. Network Characteristics, Perceived Social Support, and Psychological Adjustment in Mothers of Children with Autism Spectrum Disorder. Journal of Autism and Developmental Disorders 2012;42: 2597-2610. http://dx.doi.org/10.1007/ s10803-012-1517-9

[21] Dunst CJ, Trivette CM, Cross AH. Mediating Influences of Social Support: Personal, Family, and Child Outcomes. American Journal of Mental Deficiency 1986;90 403417.

[22] Pozo P, Sarriá E, Brioso A. Family Quality of Life and Psychological Well-Being in Parents of Children with Autism Spectrum Disorders: A Double ABCX Model. Journal of Intellectual Disability Research 2014;58(5): 442-458 http://dx.doi.org/10.1111/jir. 12042 
[23] Baxter C, Cummins RA, Yiolitis L. Parental Stress Attributed to Family Members with and without Disability: A Longitudinal Study. Journal of Intellectual and Developmental Disability 2000;25: 105-18. http://dx.doi.org/10.1080/13269780050033526

[24] Donenberg G, Baker BL. The Impact of Young Children with Externalizing Behaviours on their Families. Journal of Abnormal Child Psychology 1993;21: 179-98. http://dx.doi.org/10.1007/BF00911315

[25] Lecavalier L, Leone S, Wiltz J. The Impact of Behavior Problems on Caregiver Stress in Young People with Autism Spectrum Disorders. Journal of Intellectual Disability Research 2006;50: 172-183. http://dx.doi.org/10.1111/j.1365-2788.2005.00732.x

[26] Peters-Scheffer N, Didden R, Korzillus H. Maternal Stress Predicted by Characteristics of Children with Autism Spectrum Disorder and Intellectual Disability. Research in Autism Spectrum Disorders 2012;6(2): 696-706. http://dx.doi.org/10.1016/j.rasd. 2011.10.003

[27] Tomanik S, Harris GE, Hawkins J. The Relationship between Behaviors Exhibited by Children with Autism and Maternal Stress. Journal of Intellectual and Developmental Disability 2004;29: 16-26. http://dx.doi.org/10.1080/13668250410001662892

[28] Totsika V, Hastings RP, Emerson E, Lancaster GA, Berridge DM. A Population-Based Investigation of Behavioural and Emotional Problems and Maternal Mental Health: Associations with Autism Spectrum Disorder and Intellectual Disability. Journal of Child Psychology and Psychiatry 20011;52(1): 91-99. http://dx.doi.org/10.1111/j. 1469-7610.2010.02295.x.

[29] Essex E, Seltzer M, Krauss M. Differences in Coping Effectiveness and Well-Being among Aging Mothers and Fathers of Adults of Mental Retardation. American Journal on Mental Retardation 1999;104: 545-563. Available from http://www.waisman.wisc.edu/family/pubs/AgingDD/5\%20-

\%20AJMR_1999_differences_in_coping.pdf (accessed 14 March 2014).

[30] Hastings RP, Kovshoff H, Brown T, Ward NJ, degli Espinosa F, Remington B. Coping Strategies in Mothers and Fathers of Preschool and School-Age Children with autism. Autism 2005;9: 377-391. http://dx.doi.org/10.1177/1362361305056078

[31] Pozo P, Sarriá E. Prediction of Stress in Mothers of Children with Autism Spectrum Disorders. Spanish Journal of Psychology 2014;17(e6): 1-12. http://dx.doi.org/10.1017/ sjp.2014.6

[32] Smith L, Hong A, Seltzer M, Greenberg J, Almeida D, Bishop S. Daily Experiences among Mothers of Adolescents and Adults with ASD. Journal of Autism and Developmental Disorders 2010;40: 167-178. http://dx.doi.org/10.1007/s10803-009-0844-y

[33] Saloviita T, Itaelinna M, Leinonen E. Explaining the Parental Stress of Fathers and Mothers Caring for a Child with Intellectual Disability: A Double ABCX Model. Jour- 
nal of Intellectual Disability Research 2003;47: 300-312. http://dx.doi.org/10.1046/j. 1365-2788.2003.00492.x

[34] Bristol M. Mothers of Children with Autism or Communication Disorders: Successful Adaptation and the Double ABCX Model. Journal of Autism and Developmental Disorders 1987;17: 469-486.

[35] Oelofsen N, Richardson P. Sense of Coherence and Parenting Stress in Mothers and Fathers of Preschool Children with Developmental Disability. Journal of Intellectual and Developmental Disability 2006;31(1): 1-12. http://dx.doi.org/ $10.1080 / 13668250500349367$

[36] Weiss MJ. Hardiness and Social Support as Predictors of Stress in Mothers of Typical Children, Children with Autism and Children with Mental Retardation. Autism 2002;6: 115-130. http://dx.doi.org/10.1177/1362361302006001009

[37] Helf CM, Glidden LM. More Positive or Less Negative? Trends in Research on Adjustment of Families Rearing on Children with Developmental Disabilities. Mental Retardation 1998;36(6): 457-464. http://dx.doi.org/ 10.1352/0047-6765(1998)036<0457:MPOLNT>2.0.CO;2

[38] Gardiner E, Iarocci G. Unhappy (and Happy) in their own Way: A Developmental Psychopathology Perspective on Quality of Life for Families Living with Developmental Disability with and without Autism. Research in Developmental Disabilities 2012; 33: 2177-2192. http://dx.doi1.org/0.1016/j.ridd.2012.06.014

[39] Karst JS, Van Hecke AV. Parent and Family Impact of Autism Spectrum Disorders: A Review and Proposed Model for Intervention Evaluation. Clinical Child Family Psychology Review 2012;15: 247-277. http://dx.doi.org/10.1007/s10567-012-0119-6.

[40] Antonovsky, A. The Structure and Properties of the Sense of Coherence Scale. Social Science and Medicine 1993;36: 725-733. http://dx.doi.org/10.1016/0277-9536(93)90033Z

[41] Behr S, Murphy D. Research Progress and Promise: The Role of Perceptions in Cognitive Adaptation to Disability. In: Turnbull A, Patterson JM, Behr S, Murphy D, Marquis J, Blue-Banning M. (eds.) Cognitive Coping, Families, and Disability. Baltimore: Paul H. Brookes Publishing; 1993. p151-163.

[42] Hastings RP, Taunt HM. Positive Perceptions in Families of Children with Developmental Disabilities. American Journal on Mental Retardation 2002;107: 116-127.

[43] Heiman H. Parents of Children with Disabilities: Resilience, Coping, and Future Expectations. Journal of Developmental and Physical Disabilities 2002;14(2): 159-171. http://dx.doi.org/1056-263X/02/0600-0159/0

[44] Kausar S, Jevne RF, Sobsey D. Hope in Families of Children with Developmental Disabilities. Journal of Developmental Disabilities 2003;10: 35-46. 
[45] Myers BJ, Mackintosh VH, Goin-Koc hel, RP. "My Greatest Joy and my Greatest Heartache:" Parents' Own Words on How Having a Child in the Autism Spectrum Has Affected their Lives and their Families' Lives. Research in Autism Spectrum Disorders 2009;3 670-684. http://dx.doi.org/10.1016/j.rasd.2009.01.004

[46] O'Connor S. We're All One Family: The Positive Construction of People with Disabilities by Family Members. In: Taylor SJ, Bogdan R, Lutfiyya ZM. (eds.) The Variety of Community Experience: Qualitative Studies of Family and Community Baltimore: Paul H. Brookes Publishing; 1995. p67-77.

[47] Scorgey K, Sobsey D. Transformational Outcomes Associated with Parenting Children who Have Disabilities. Mental Retardation 2000;38: 195-206. http://dx.doi.org/ 10.1352/0047-6765(2000)038<0195:TOAWPC >2.0.CO;2

[48] Trute B, Hiebert-Murphy D, Levineb K. Parental Appraisal of the Family Impact of Childhood Developmental Disability: Times of Sadness and Times of Joy. Journal of Intellectual and Developmental Disability 2007;32: 1-9. http://dx.doi.org/ $10.1080 / 13668250601146753$

[49] Mullins JB. Authentic Voices from Parents of Exceptional Children. Family Relations 1987;36: 30-33.

[50] Hornby GA. Review of Fathers Accounts of their Experiences of Parenting Children with Disabilities. Disability, Handicap, and Society 1992;7: 363-374.

[51] Behr SK, Murphy DL, Summers JA. (1992). User's Manual: Kansas Inventory of Parental Perceptions (KIPP). Lawrence, KS: Beach Center on Families and Disability; 1992. Available from http://beachcenter.org/books/FullPublications/PDF/KIPP.pdf (accessed 12 October 2013).

[52] Hastings RP, Allen R, McDermott K, Still D. Factors Related to Positive Perceptions in Mothers of Children with Intellectual Disabilities. Journal of Applied Research in Intellectual Disabilities 2002;15: 269-275. http://dx.doi.org/10.1046/j. 1468-3148.2002.00104.x

[53] Werner S, Shulman S. Subjective Well-being among Family Caregivers of Individuals with Developmental Disabilities: The Role of Affiliate Stigma and Psychosocial Moderating Variables. Research in Developmental Disabilities 2013;34: 4103-4114. http:// dx.doi.org/10.1016/j.ridd.2013.08.029

[54] Kayfitz AD, Gragg MN, Orr RR. Positive Experiences of Mothers and Fathers of Children with Autism. Journal of Applied Research in Intellectual Disabilities 2010;23: 337-343. http://dx.doi.org/10.1111/j.1468-3148.2009.00539.x

[55] Pozo P, Sarriá E, Brioso A. Psychological Adaptation in Parents of Children with Autism Spectrum Disorders. In: Mohammadi MR. (ed.) A Comprehensive Book on Autism Spectrum Disorders. Rijeka: InTech; 2011. p107-130. Available from http:// www.intechopen.com/books/a-comprehensive-book-on-autism-spectrum-disorders/ 
psychological-adaptation-in-parents-of-children-with-autism-spectrum-disorders (accessed 1 April 2014).

[56] Hastings RP, Kovshoff H, Ward NJ, degli Espinosa F, Brown T, Remington B. Systems Analysis of Stress and Positive Perceptions in Mothers and Fathers of PreSchool Children with Autism. Journal of Autism and Developmental Disorders 2005;35: 635-644. http://dx.doi.org/10.1007/s10803-005-0007-8

[57] Braunstein VL, Peniston N, Perelman A, Cassano MC. The Inclusion of Fathers in Investigations of Autistic Spectrum Disorders. Research in Autism Spectrum Disorders 2013;7: 858-865. http://dx.doi.org/10.1016/j.rasd.2013.03.005

[58] Bristol M, Gallagher JJ, Schopler E. Mothers and Fathers of Young Developmentally Disabled and Nondisabled Boys: Adaptation and Spousal Support. Developmental Psychology 1988;24(3): 441-451.

[59] Gray, D. E., \& Holden, W. J. (1992). Psycho-social Well-being among Parents of Children with Autism. Australia and New Zealand Journal of Developmental Disabilities 1992;18: 83-93. http://dx.doi.org/10.1080/07263869200034841

[60] Herring S, Gray K, Taffe J, Tonge B, Sweeney D, Einfeld S. Behavior and Emotional Problems in Toddlers with Pervasive Developmental Disorders and Developmental Delay: Associations with Parental Mental Health and Family Functioning. Journal of Intellectual Disability Research 2006;50: 374-382. http://dx.doi.org/10.1111/j. 1365-2788.2006.00904.x

[61] Trute B. Gender Differences in the Psychological Adjustment of Parents of Young Developmentally Disabled Children. Journal of Child Psychology and Psychiatry 1995;36(7): 1225-1242. http://dx.doi.org/10.1111/j.1469-7610.1995.tb01367.x

[62] Bayat M. How Family Members' Perceptions of Influences and Causes of Autism May Predict Assessment of their Family Quality of Life. Dissertation Abstracts International: Section B: The Sciences and Engineering 2005;66: 57-79.

[63] Wang M, Summers JA, Little T, Turnbull, A, Poston, D, Mannan H. Perspective of Fathers and Mothers of Children in Early Intervention Programs in Assessing Family Quality of Life. Journal of Intellectual Disability Research 2006;50: 977-988. http:// dx.doi.org/10.1111/j.1365-2788.2006.00932.x

[64] Rivard M, Terroux A, Parent-Bousier C, Mercier C. (2014, in press). Determinants of Stress in Parents of Children with ASD. Journal of Autism and Developmental Disorders. http://www.doi.org/10.1007/s10803-013-2028-z\#sthash.SGDiCpkB.dpuf

[65] Ayuda-Pascual R, Llorente-Comí M, Martos-Pérez J, Rodríguez-Bausá L, Olmo-Remesal L. Medidas de Estrés e Impacto Familiar en Padres de Niños con Trastornos del Espectro Autista antes y después de su Participación en un Programa de Formación. Revista de Neurología 2012;54(1): S73-80. Available from http://www.neurologia.com/pdf/Web/54S01/bhS01S073.pdf (accessed 20 January 2014). 
[66] Brookman-Frazee L, Koegel R. Using Parent/Clinician Partnerships in Parent Education Programs for Children with Autism. Journal of Positive Behavior Interventions 2004;6(4): 195-213. http://www.doi.org/10.1177/10983007040060040201

[67] Molteni P, Maggiolini S. Parent's Perspectives towards the Diagnosis of Autism: An Italian Case Study Research. Journal of Child and Family Studies 2014;in press http:// dx.doi.org/10.1007/st0826-014-9917-4

[68] Navarro-Martínez E, Valdez-Sierra MD, Soltero-Rodríguez N, Zambrano-Guzmán R, Nava-Bustos G, Sandoval-Martínez J. Programa de Entrenamiento Cognitivo Conductual para Padres de Niños con Trastorno del Espectro Autista. Revista de Educación y Desarrollo 2013;25: 71-76 Available from http://www.cucs.udg.mx/revistas/ edu_desarrollo/anteriores/25/025_Navarro.pdf (accessed 3 March 2014)

[69] Singer GHS, Ethridge BL, Aldana SI. Primary and Secondary Effects of Parenting and Stress Management Interventions for Parents of Children with Developmental Disabilities: A Meta-analysis. Mental Retardation and Developmental disabilities. Research Reviews 2007;13: 357-369. http://dx.doi.org/10.1002/mrdd.20175

[70] Tonge B, Brereton A, Kiomall M, Mackinnon A, King N, Rinehart, N. Effects on Parental Mental Health of an Education and Skills Training Program for Parents of Young Children with Autism: A Randomized Controlled Trial. Journal of the American Academy of Child and Adolescent Psychiatry 2006;45: 561-569. http://dx.doi.org/ 10.1097/01.chi.0000205701.48324.26

[71] Dyches TT, Smith TB, Korth BB, Susanne OR, Mandleco B. Positive Parenting of Children with Developmental Disabilities: A Meta-analysis. Research in Developmental Disabilities 2012;33: 2213-2220. http://dx.doi.org/10.1016/j.ridd.2012.06.015

[72] Greenberg JS, Seltzer MM, Hong J, Orsmond GI. Bidirectional Effects of Expressed Emotion and Behavior Problems and Symptoms in Adolescents and Adults with Autism. American Journal on Mental Retardation 2006;111: 229-249. Available from http://www.waisman.wisc.edu/family/pubs/autism/2006_bidirectional.pdf (accessed 15 December 2013).

[73] Rojahn J, Matson JL, Lott D, Svensen A, Smalls Y. The Behaviour Problems Inventory: An Instrument for the Assessment of Self-injury, Stereotyped Behaviour, and Aggression/Destruction in Individuals with Developmental Disabilities. Journal of Autism and Developmental Disorders 2001;31: 577-588. http://dx.doi.org/10.1023/A: 1013299028321

[74] Bristol M. Maternal Coping with Autistic Children: The Effects of Child Characteristics and Interpersonal Support. PhD Thesis. North Carolina: University of Chapel Hill; 1979.

[75] Carver CS. You Want to Measure Coping but your Protocol's Too Long: Consider the Brief COPE. International Journal of Behaviour Medicine 1997;4: http:// dx.doi.org/92-100. 10.1207/s15327558ijbm0401_6 
[76] Crespo M, Cruzado JA. La Evaluación del Afrontamiento: Adaptación Española del Cuestionario COPE con una Muestra de Estudiantes Universitarios. Análisis y Modificación de Conducta 1997;23: 797-830.

[77] Díaz D, Rodríguez-Carvajal R, Blanco A, Moreno-Jiménez B, Gallardo I, Valle C, et al. Adaptación Española de las Escalas de Bienestar Psicológico de Ryff. Psicothema 2006;18: 572-77. Available from http://www.psicothema.com/pdf/3255.pdf (accessed 28 October 2013).

[78] Ryff C, Keyes C. The Structure of Psychological Well-being Revisited. Journal of Personality and Social Psychology 1995;69: 719-727. Available from http:// www.midus.wisc.edu/findings/pdfs/830.pdf (accessed 15 October 2013).

[79] Poston DJ, Turnbull AP, Park J, Mannan H, Marquis J, Wang M. Family Quality of Life: A Qualitative Inquiry. Mental Retardation 2003;41: 313-328. Available from http://www.beachcenter.org/research/FullArticles/PDF/FQL3_Family\%20Quality \%20of\%20Life.pdf (accessed 15 October 2013).

[80] Sainz F, Verdugo MA, Delgado A. Escalas de Calidad de Vida Familiar. Spanish Adaptation Family Quality of Life Survey. Salamanca: INICO, Universidad de Salamanca; 2005. Available from http://sid.usal.es/idocs/F8/FDO26164/herramientas_6.pdf (accessed 28 October 2013).

[81] Faul F, Erdfelder E, Buchner A, Lang AG. Statistical Power Analyses Using G*Power 3.1: Tests for Correlation and Regression Analyses. Behavior Research Methods 2009;41: 1149-1160. http://dx.doi.org/10.3758/BRM.41.4.1149

[82] Cohen JA. Power Primer. Psychological Bulletin 1992;112: 155-159. http://dx.doi.org/ 10.1037/0033-2909.112.1.155

[83] Baker DL, Dapela, LA. Mostly the Mother: Concentration of Adverse Employment Effects on Mothers of Children with Autism. The Social Science Journal 2010;47(3): 578-592. http://dx.doi.org/10.1016/j.soscij.2010.01.013

[84] Pisula E, Kossakowska Z. Sense of Coherence and Coping with Stress among Mothers and Fathers of Children with Autism. Journal of Autism and Developmental Psychology $2010 ; 40$ : 1485-94. http://dx.doi.org/10.1007/s10803-010-1001-3

[85] Sivberg B. Coping Strategies and Parental Attitudes: A Comparison of Parents with Children with Autistic Spectrum Disorder and Parents with Non-Autistic Children. International Journal of Circumpolar Health, 2002;61(2): 36-50. Available from http:// journals.co-action.net/index.php/ijch/article/viewFile/17501/19910 (accessed 23 January 2014).

[86] Twoy R, Connolly PM, Novak JM. Coping Strategies Used by Parents of Children with Autism. Journal of the American Academy of Nurse Practitioner 2007;19: 251260. http://dx.doi.org/10.1111/j.1745-7599.2007.00222.x 
[87] Patterson J. Understanding Family Resilience. Journal of Clinical Psychology 2002;58: 233-246. http://dx.doi.org/10.1002/jclp.10019 
